\title{
Captação de Múltiplos Órgãos: os Desafios do Processo para os Profissionais da Saúde e Familiares \\ Naianne Figueredo Leite ${ }^{1}$; Thércia Lucena Grangeiro Maranhão ${ }^{2}$; Athena de Albuquerque Farias ${ }^{3}$
}

\begin{abstract}
Resumo: O artigo teve como objetivo analisar os aspectos que envolvem profissionais da saúde e familiares no processo de Captação de Múltiplos Órgãos na perspectiva dos enfermeiros, tendo como objetivos específicos: compreender o processo para diagnosticar a morte encefálica, como é feita a entrevista dos enfermeiros com os familiares enlutados para a possibilidade de doação de órgãos e constatar, na perspectiva do enfermeiro, o papel do psicólogo no suporte emocional aos familiares durante o processo de captação de órgãos. Foi realizada uma pesquisa de campo, de abordagem qualitativa, descritiva e exploratória. A coleta dos dados ocorreu no Hospital Regional do Cariri, por meio de entrevista contendo dez perguntas. As respostas foram avaliadas a partir da análise de conteúdo, sendo estabelecidas quatro categorias: o procedimento utilizado na abordagem familiar; Dúvidas dos familiares quanto à doação de órgãos; Principais desafios dos profissionais da saúde no processo de captação de órgãos; Importância do profissional psicólogo na equipe multidisciplinar da Organização de Procura de Órgãos. A partir dos resultados obtidos foi possível chegar as seguintes conclusões: o diagnóstico de morte encefálica é realizado pelos médicos. O maior desafio encontrado pelos profissionais é a abordagem familiar, logo após o diagnostico, é realizada uma entrevista com a família para a possível doação de órgãos. Destaca-se a necessidade de serem desenvolvidas mais pesquisas nesta linha para melhorar o amparo aos envolvidos no processo.
\end{abstract}

Palavras-chave: Morte encefálica. Captação de órgãos. Entrevista familiar. Psicólogo.

\section{Multiple Organ Procurement: The Process Challenges for Health Professionals and Relatives}

\begin{abstract}
The objective of the article was to analyze the aspects that involve health professionals and family members in the process of Multiple Organ Removal from the point of view of the nurses, the specific objectives were: to understand the process to diagnose the brain death, how nurses interview the bereaved to the possibility of organ donation and to verify, from the point of view of the nurse, the role of the psychologist in the emotional support to the relatives during the process of organ removal. A field research was done, with a qualitative, descriptive and exploratory approach. The data collection was happened at the Cariri Regional Hospital through interviews had ten questions. The answers were evaluated based on content analysis and four categories were established: the procedure used in the family approach; Doubts of the relatives regarding the organ donation; Main challenges for health professionals in the organ removal process; Importance of the professional psychologist in the multidisciplinary team of the Organ Removal Organization. From the results obtained it was possible to reach the following conclusions: the diagnosis of brain death is done by the physicians. The greatest challenge encountered by professionals is the family approach, soon after the diagnosis, an interview with the family is realized for the possible organ donation. It is worth highlighting the need to develop more researches like this to improve the support to those involved in the process.
\end{abstract}

Keywords: Brain death. Organ retrieval. Family interview. Psychologist.

\footnotetext{
${ }^{1}$ Graduanda do curso de Psicologia do Centro Universitário Doutor Leão Sampaio (UniLeão).

E-mail: naiannefl@outlook.com;

${ }^{2}$ Psicóloga, Graduada pela Faculdade de Ciências Humanas de Recife - ESUDA. Especialista em Gestão do Trabalho e da Educação na Saúde pela Escola de Saúde Pública do Estado do Ceará. Aluna do Programa de Pós- Graduação da Faculdade de Medicina do ABC, do curso de Mestrado em Ciências da Saúde. Professora do Centro Universitário Dr. Leão Sampaio.

E-mail: thercia@leaosampaio.edu.br

${ }^{3}$ Graduação em Direito pela Faculdade Guararapes. Pernambuco, Brasil. E-mail: athena.farias@gmail.com.
} 
Id on Line Revista Multidisciplinar e de Psicologia

Id on Line Multidisciplinary and Psycology Journal

\section{Introdução}

A evolução científica trouxe a multiplicação dos tipos de tratamentos para as mais variadas doenças. Deste modo, o surgimento do transplante de órgãos, de tecidos e de partes do corpo humano assinala um avanço no campo da medicina. Com esses inúmeros avanços, tornou o transplante um procedimento terapêutico seguro, pois possibilita a reabilitação física e social do paciente (FURLAN et al., 2015). A lei $\mathbf{n}^{\mathbf{0}} \mathbf{9 . 4 3 4}$, de 4 de fevereiro de 1997 estabelece que a retirada de tecidos, de órgãos ou de partes do corpo humano destinados a transplante ou tratamento deverá ser precedida de diagnóstico de morte encefálica, constatada e registrada por dois médicos não participantes das equipes de remoção e transplante, mediante a utilização de critérios clínicos e tecnológicos definidos por resolução do Conselho Federal de Medicina. A lei no 10.211, de 23 de março de 2001, permite a autorização do procedimento através de um cônjuge ou de um parente, maior de idade, obedecida a linha sucessória, reta ou colateral, até o segundo grau inclusive, firmada em documento subscrito por duas testemunhas presentes à verificação da morte (BRASIL, 1997).

A morte encefálica se tornou uma condição essencial para a possível realização do transplante de órgãos e de tecidos, de modo que se faz necessário o desenvolvimento de seu conceito. Ela é caracterizada pela parada total e irreversível das funções cerebrais. As funções cardíacas e respiratórias só serão possíveis através de meios artificiais, isto é, com o auxílio de aparelhos, caracterizando, assim, a morte clínica do indivíduo (NORONHA et al., 2012).

Diante dos benefícios que o transplante proporciona, o reconhecimento e a notificação da morte encefálica são um dos protocolos mais importantes no cenário atual da saúde (DE JESUS SOUZA et al., 2016). Aguiar et al. (2011) afirma que a abrangência de profissionais da saúde envolvidos no processo de doação é em virtude da busca de ações para diminuir a perda do potencial doador, visando elevar o número de doações e reduzir o sofrimento de pessoas na fila de espera.

Deste modo, a Organização de Procura de Órgãos (OPO) fez expansão do território geográfico e populacional para a atuação do processo doação/transplante. Vale ressaltar que é importante a OPO ter seus limites de atuação determinados por critérios populacionais e 
Id on Line Revista Multidisciplinar e de Psicologia

Id on Line Multidisciplinary and Psycology Journal

geográficos, proporcionando a detecção e viabilização do potencial doador de órgãos (VIEIRA e NOGUEIRA, 2016).

A OPO se encontra na sede do Hospital Regional do Cariri e faz a cobertura em mais dois Hospitais na macrorregião do Cariri: Hospital Maternidade São Vicente de Paula e Hospital Maternidade Santo Antônio em Barbalha - CE. Os órgãos e tecidos que são captados, após a constatação da morte encefálica e consentimento familiar, são rins, fígado, pâncreas, coração e córneas.

Diante do exposto acima, surge o seguinte questionamento: Como se dá o papel dos profissionais da saúde perante a família, no processo de captação de múltiplos órgãos?

A fim de responder tal questionamento pretende-se como objetivo geral analisar os aspectos que envolvem profissionais da saúde e familiares no processo de Captação de Múltiplos Órgãos na perspectiva dos enfermeiros. Observa-se como objetivos da pesquisa: compreender o processo para diagnosticar a morte encefálica; como é feita a entrevista dos enfermeiros com os familiares enlutados para a possibilidade de doação de órgãos; constatar, na perspectiva do enfermeiro, o papel do psicólogo no suporte emocional aos familiares durante o processo de captação de órgãos.

A motivação para o estudo partiu de dados da literatura relacionados às dificuldades dos profissionais para a captação de órgãos, à falta de informação das pessoas sobre a doação de órgãos e ao modo que é feito o acompanhamento e a entrevista familiar no processo de doação. Pretende-se compreender como se dá a interação dos profissionais da saúde com os familiares, verificando a possível contribuição do Psicólogo nesse processo, não esgotando o tema, desejase que esse trabalho possa ajudar em uma melhor compreensão sobre a doação de órgãos e estimule a fazerem mais pesquisas relacionado ao mesmo.

\section{A morte e a família enlutada}

Há séculos, as funções cardíacas e pulmonares eram conhecidas como fundamentais para a sobrevivência, entretanto, atualmente, o conceito de morte não está restrito a tal fato, já que existe a possibilidade de manutenção das funções vitais do ser humano, mesmo sem o 
Id on Line Revista Multidisciplinar e de Psicologia

Id on Line Multidisciplinary and Psycology Journal

funcionamento do encéfalo. Com base em rigorosos critérios neurológicos de avaliação, a morte evoluiu para o que se conhece na atualidade como morte encefálica (FREIRE et al., 2012).

Partindo do pressuposto acima, Feliú (2009) discorre que a aceitação da morte de pessoas próximas acontece de maneira gradual e lenta. $\mathrm{O}$ envolvimento com a pessoa falecida, como se ainda pudesse estar viva, e os sentimentos de revolta e negação da realidade persistem entre os familiares até que haja a aceitação da perda e a superação do luto.

O processo de luto, apesar de conter reações de tristeza e pesar culturalmente esperadas, implica na experiência do sofrimento, da dor moral, da privação consequente a perda, e pode envolver diferentes níveis de sofrimento e impacto na vida diária. Há, deste modo, uma necessidade de apoio no sentido da manifestação de solidariedade e de apoio psicológico na vivencia do luto. Pode-se sugerir que o acompanhamento especializado é potencialmente favorável em termos de saúde integral. (PARKES, 1998; OSSWALD, 2016). Assim, o processo de elaboração do luto se mostra com um canal de compreensão sobre a dor e sofrimento do ser humano vivido diante a perda de um ente querido (AZEVEDO e PEREIRA, 2014).

São vários fatores que influenciam a reação de cada pessoa em decorrência de uma perda importante. $\mathrm{O}$ enlutado enfrenta a necessidade de entender a ausência da pessoa amada, a redefinição do próprio papel na família e a inexatidão do que se perde (FUKUMITSU e KOVÁCS, 2016).

Tal afirmativa fortifica a compreensão do luto enquanto um verdadeiro processo, com início, meio e fim, repleto de fases pelas quais a família transita. Assim, com um andamento lento e gradual, a família caminha para a fase da aceitação como descreve (KÜBLER-ROSS 1996).

Percebe-se que, ao se pensar sobre o cuidado emocional, é relevante refletir sobre as possibilidades de atenção psicossocial aos familiares enlutados, compreendidas como ações direcionadas ao acolhimento e à mudança. Consideram-se as pessoas envolvidas e sua rede de relações sociais, de forma a oferecer condições que sustentem a continuidade de seu desenvolvimento (MIRANDA AFONSO, 2011).

De acordo com Kramer et al. (2010), é precária a investigação sobre como o conflito familiar e as experiências de prestação de cuidados no final da vida podem influenciar o processo de luto dos familiares. 
Um bom funcionamento familiar durante a fase de prestação de cuidados ao doente e, principalmente, no luto é importante para o bem-estar psicológico dos seus membros (DELALIBERA et al., 2015).

Segundo Roza et al. (2010), o corpo representa a memória da vida passada, que deveria ser guardada tão próxima quanto possível da pessoa amada. Os familiares acreditam que, ao concordarem com a doação de órgãos, estará desrespeitando o corpo do familiar morto, como se estivessem perdendo toda a gama de sentimentos vinculada ao físico.

\section{A família e o processo de doação}

De acordo com Siminoff et al. (2011) a entrevista familiar é um momento delicado no processo de doação porque concretiza a morte, a separação e a impotência para a família. Há uma orientação crescente de que somente pessoas treinadas especificamente para essa tarefa devam realizá-la.

Observa-se que, ao longo dos anos, o número de doações tem aumentado. No entanto, ainda não é suficiente para reduzir a lista de espera nos hospitais, cabendo, então, a reflexão acerca da dificuldade do processo. Diversos são os motivos que afetam a doação de órgãos, sugerindo a recusa dos familiares e não a notificação de possíveis doadores. Assim, vale ressaltar a importância do preparo do profissional no que diz respeito à abordagem familiar. É um momento decisivo para que se possa dar seguimento ao processo de captação de órgãos, pois o sucesso da assistência prestativa à família e ao paciente faz com que os profissionais procurem, de certa forma, encontrar-se preparados, na questão de conhecimentos e emoções (CINQUE; BIANCHI, 2010b).

Partindo do exposto acima, a abordagem da família pode ser feita por um médico, enfermeiro, psicólogo ou assistente social, desde que este profissional esteja capacitado (CAJADO, 2011).

Quando o setor responsável pela captação de órgãos é informado sobre a morte encefálica, e depois que a família é comunicada, os profissionais do transplante se apresentam para o primeiro contato, para que essa família seja orientada sobre processo de doação. 
Id on Line Revista Multidisciplinar e de Psicologia

Id on Line Multidisciplinary and Psycology Journal

Geralmente é demonstrado certo desconforto, seja pela recém-anunciada perda, seja pela abordagem rápida do setor de transplante. É observada a angústia da família, que comumente retorna ao setor em busca de informações detalhadas sobre o processo de doação, expondo os seus sentimentos (CARVALHO, 2015).

A doação de órgãos e de tecidos é entendida por muitos como um ato de solidariedade e amor ao próximo, por beneficiar a qualidade de vida de pessoas doentes que aguardam o transplante. No entanto, ela só se efetiva mediante ao consentimento familiar, que permite a retirada dos órgãos e dos tecidos para fins de transplantes, conforme determina a legislação brasileira vigente (SILVA et al., 2012).

Santos (2013) afirma que a família analisa parcialmente a situação que vivencia com a morte do parente. Isso influencia diretamente no resultado da entrevista quanto à doação. Bittencourt, Quintana e Velho (2011) elucidam que é preciso que a família receba informações pertinentes e adequadas sobre o processo de doação, que possibilitem a tomada de decisão de maneira voluntária, isto é, livre de pressões externas. Nota-se que, entre a declaração de ME e a entrevista familiar, existe um caminho que, apesar de curto, é igualmente complexo e delicado.

O medo da desfiguração e da perda da integridade física do falecido faz com que a família veja a doação como uma mutilação e não como um ato cirúrgico. Os familiares, que recusa a doação, não aceitam que o corpo do falecido seja submetido à cirurgia (MORAES e MASSAROLLO 2009).

Ferrazzo et al. (2011) constatou que no Brasil existem poucos estudos que relacionam a crença religiosa à doação e transplante de órgãos. A pesquisa mostra que a não aceitação da doação se dá pelo fato de que, na maioria das culturas, corpo e alma estão interligados e a remoção de órgãos pode trazer malefícios à alma. Assim, conclui-se que a ideia de mutilação do corpo está presente e que é comum em muitas crenças relacionar agressões ao corpo com traumas para a alma e problemas para o destino espiritual.

Os fatores que facilitam ou que dificultam a entrevista se relacionam ao esclarecimento que os familiares recebem sobre os acontecimentos que envolvem o paciente, durante o período de internação. A família que é informada inicialmente, nos exames, sobre a confirmação do diagnóstico de morte encefálica, tem a possibilidade de se preparar para a morte do paciente. 
Id on Line Revista Multidisciplinar e de Psicologia

Id on Line Multidisciplinary and Psycology Journal

Porém, aquelas que recebem a notificação somente após a confirmação do diagnóstico, ficam comumente chocadas (SANTOS e MASSAROLLO, 2005; CINQUE et al., 2010a).

\section{O papel dos profissionais de saúde no processo da captação de órgãos}

De acordo com Ladessa et al. (2014) o acolhimento familiar é essencial no momento da notícia do diagnóstico da morte encefálica, para dar suporte à família ao vivenciar a perda de um ente querido e para que o assunto sobre a doação seja esclarecido. Morte encefálica é diferente de doação de órgãos, e nesse sentido, o papel do psicólogo é importante. Qualquer profissional da saúde pode fazer o acolhimento familiar, entendendo-se como um atendimento humanizado, entretanto, o psicólogo se apresenta como alguém disposto, presente e disponível, e, através de seu olhar na subjetividade, capaz de compreender o outro a partir de sua experiência e dos significados de mundo. No tocante ao atendimento da família do Doador em potencial, o psicólogo pode acompanhar desde a internação até a entrega do corpo. Em caso de doação positiva, ele pode atender à família em suas necessidades emocionais, através do acolhimento e da escuta.

O transplante de órgãos tem sido alvo de muita polêmica após a regulamentação da nova lei n. 9.434 de fevereiro de 1997, ficou estabelecida a doação presumida de órgãos:

Art. $3^{\circ}$ A retirada post mortem de tecidos, órgãos ou partes do corpo humano destinados a transplante ou tratamento deverá ser precedida de diagnóstico de morte encefálica, constatada e registrada por dois médicos não participantes das equipes de remoção e transplante, mediante a utilização de critérios clínicos e tecnológicos definidos por resolução do Conselho Federal de Medicina (BRASIL, 1997, p.1).

A valorização do preparo da equipe multiprofissional é importante e necessária, pois o sucesso da efetividade da doação de órgãos e de tecidos é diretamente proporcional à precocidade da notificação da morte encefálica (FREIRE et al., 2014).

A situação de crise vivida pelos familiares dos possíveis doadores pode ser observada pela desorganização das relações interpessoais devido à distância física do paciente, às dificuldades financeiras e ao medo da morte da pessoa querida. O momento vivido na UTI é intenso e de bastante estresse, desamparo, medo, pânico, irritação, entre outros. A 
Id on Line Revista Multidisciplinar e de Psicologia

Id on Line Multidisciplinary and Psycology Journal

hospitalização pode gerar o desequilíbrio do sistema familiar, provocando sobrecarga e sofrimento emocional. (SOUZA, 2010).

Com isso, a sobrecarga física e psicológica que recai sobre os familiares deve ser acompanhada pela equipe de saúde, a fim de que o luto possa ser preparado de modo saudável (GUIMARÃES e LIPP, 2011; MELO et al., 2012). O acompanhamento deve ser oferecido, de maneira especial, pelas equipes que atuam com os cuidados paliativos (PALMEIRA et al., 2011).

A equipe de captação mantém contato direto com os familiares durante o período de internação do potencial doador, sendo que estabelece vínculos com os mesmos. No momento da perda, é importante disponibilizar o auxílio psicológico para a família, a fím de minimizar o sofrimento, preparando-a para uma aceitação gradual da morte inesperada de seu ente querido (FERNANDES, DE CAMARGO BITTENCOURT; BOIN, 2015).

O psicólogo pode auxiliar os familiares na reunião com os profissionais e na elaboração das informações do quadro clínico. Pode também proporcionar a possibilidade para a realização de rituais de despedida, ajudando-os na expressão sobre a perda do ente querido e na doação de órgãos (TORRES e LAGE, 2013).

\section{Processo de captação de múltiplos órgãos}

No Brasil, há grandes esforços políticos, sociais, governamentais e não governamentais com o sentido de aumentar o número de doações efetivadas e de pacientes transplantados (MENDES et al., 2012; DELL AGNOLO et al., 2012; CINQUE e BIANCHI, 2010b; MARINHO et al., 2011).

A morte encefálica (ME) é definida como a parada completa e irreversível das funções encefálicas, impossibilitando a manutenção da vida sem o auxílio de meios artificiais. O conceito de morte encefálica não é essencial apenas para o transplante de órgãos, como também é uma forma de não prolongar o sofrimento e a angústia dos familiares do paciente, independentemente de serem favoráveis ou não à doação de órgãos (WIJDICKS, 2001; 2010). 
Id on Line Revista Multidisciplinar e de Psicologia

Id on Line Multidisciplinary and Psycology Journal

A notificação de morte encefálica é obrigatória e está prevista por lei desde 1992 . O Conselho Regional de Medicina, na resolução $n^{\circ} 1.480$, define que para ser realizado o diagnóstico de ME são necessários 2 testes clínicos e exame complementar de acordo com a faixa etária. Esse processo tem duração em torno de 12 à $36 \mathrm{~h}$ da suspeita à confirmação (LADESSA et al., 2014). A partir do conhecimento do número de ME em cada instituição, é possível identificar as verdadeiras possibilidades de notificação (KNIHS et al., 2015).

Existem fatores que impedem a realização da doação, pode-se, então, citar a falta de notificação de mortes encefálicas e as falhas na manutenção dos órgãos para a captação. Nesse sentido, a busca de ações para diminuir a perda do potencial doador, como também aumentar o número de doações e reduzir a angústia das pessoas que estão na fila de espera, torna-se um caminho para a resolução das problemáticas. Ressalta-se a importância da capacitação de profissionais de saúde envolvidos no processo de doação (AGUIAR et al., 2010; KNIHS, SCHIRMER e ROZA, 2011).

Mesmo diante do avanço na transplantação, e de o Brasil possuir um protocolo sistemático e legal para o diagnóstico de morte encefálica (ME), nota-se a persistência de um desequilíbrio crescente entre a oferta e a demanda de órgãos (MORATO 2009; BRASIL, 2011; USA, 2014).

De acordo com Roza et al. (2009), as ações de melhoria, garantindo uma sequência ético-legal que já é definida na lei e no decreto dos transplantes, pressupõem o compromisso com a qualidade e com a segurança do processo de doação de órgãos e tecidos, que deve ser rigorosamente perseguida pelos profissionais que trabalham na área.

\section{Metodologia}

Foi realizada uma pesquisa de campo de abordagem qualitativa, descritiva e exploratória, contudo a pesquisa iniciou propriamente através da busca ativa de informações nas bases de dados do Centro Latino-americano e do Caribe de Informação em Ciências da Saúde (BIREME), PUBMED, MEDLINE, e LILACS, além da biblioteca virtual SciELO. Buscou-se realizar um levantamento sistemático sobre o tema central deste trabalho: o 
Id on Line Revista Multidisciplinar e de Psicologia

Id on Line Multidisciplinary and Psycology Journal

transplante de órgãos, desde o processo de captação até a abordagem familiar. Utilizou-se, para a pesquisa, o descritor transplante de órgãos, sendo este em ciência da saúde, identificado no DeCS. Tem como sinônimos em português: enxerto de órgão, enxertos de órgãos, transplantação de órgão e transplantação de órgãos. Sua definição para o português é a transferência de um órgão entre indivíduos de uma mesma espécie ou entre os indivíduos de espécies diferentes.

Com a finalidade de delimitar o objeto de estudo e o campo de investigação para a realidade que se pretende apreender, optou-se por selecionar apenas produções na forma de artigos publicados em periódicos nacionais. Os artigos foram selecionados de maneira aleatória, ou seja, de acordo com o surgimento a partir do uso das palavras-chave. Inicialmente, foi selecionado artigos por títulos e resumos.

Os descritores de assunto utilizados para a busca de artigos sobre "processo de captação de múltiplos órgãos e a abordagem familiar" foram: captação de múltiplos órgãos, família, doação de órgãos e organização de procura de órgãos. Utilizou-se a interseção dos conjuntos (descritores do assunto e ano de publicação).

A seleção se baseou na conformidade dos limites dos assuntos aos objetivos deste trabalho, desconsiderados aqueles artigos que, apesar de aparecerem no resultado da busca, não abordavam o assunto sob o ponto de vista do processo de captação de órgãos e do sentimento das famílias. Os artigos selecionados foram caracterizados segundo o tipo de estudo realizado, o local da realização da pesquisa, o ano de publicação, o uso de programas estatísticos, a metodologia utilizada e os resultados encontrados.

A pesquisa qualitativa é "interpretativa, baseada em experiências, situacional e humanística", sendo consistente com suas prevalências de particularidade e contexto (STAKE, 2011, p. 41). Já as pesquisas descritivas têm como objetivo descrever minunciosamente os fatos e os fenômenos de algum fato, de forma a obter informações sobre o que já foi definido como problema a ser examinado (TRIVIÑOS, 2008).

Na visão de Gil (2010, p. 27), as pesquisas exploratórias têm como objetivo garantir um maior conhecimento sobre o problema, tendo em vista torná-lo mais esclarecedor ou construir hipóteses. Seu planejamento tende a ser bastante compreensivo, pois interessa avaliar os mais variados aspectos referentes ao fato ou elemento estudado. 
Para iniciar a pesquisa foi necessário a realização de um Projeto contendo todos os critérios estipulados pelo HRC. Foi necessário também, a assinatura de alguns termos exigidos pelo HRC para assim o projeto ser submetido a um Comitê Parcial do mesmo, e dado a aprovação, o projeto foi submetido também ao Comitê de Ética da UNILEÃO. Recebido a autorização da Instituição e aprovação do Comitê de Ética em Pesquisa (CAAE: 60833516.3.0000.5048), foi apresentado o termo de consentimento livre e esclarecido (TCLE) para sujeitos da pesquisa do HRC.

Após a assinatura dos termos procedeu-se a coleta de dados através de uma entrevista semiestruturada e individual, contendo dez questões, as quais foram gravadas e transcritas com fidedignidade a fala dos profissionais. Tinha-se como foco, obter informações detalhadas sobre o procedimento de captação de órgãos, desafios para familiares e profissionais de saúde da equipe multiprofissional, a experiência vivida pelos enfermeiros junto às suas práticas, como a possível colaboração do psicólogo inserido na equipe multiprofissional do Hospital Regional do Cariri. No entanto foram definidas pelo autor como: E1 , E2, E3, E4, E5.

O profissional precisava ter experiência com captação de no mínimo 2 anos e assim será classificado como bom. Se este obtivesse 3 a 5 anos de trabalho no processo citado, será considerado muito bom. O tempo menor que 2 anos de experiência será desconsiderado. A coleta de dados aconteceu no mês seguinte após a aprovação do Comitê de Ética em Pesquisa no ano de 2016.

Para tratar os dados da pesquisa, foi utilizada a análise de conteúdo que, de acordo com Silva e Fossá (2015), é uma técnica de análise das comunicações, que irá avaliar o que foi dito nas entrevistas ou percebido pelo pesquisador.

\section{Análise e Discussão}

Os membros da equipe de enfermagem responsável pelo processo de captação de órgãos eram, em sua maioria, graduados há mais de cinco anos. Apenas um dos entrevistados tinham

\footnotetext{
*Enfermeiro entrevistado número 1. As próximas classificações seguem o mesmo padrão.
} 
Id on Line Revista Multidisciplinar e de Psicologia

Id on Line Multidisciplinary and Psycology Journal

entre 2 e 5 anos de graduação. Todos atuavam no Hospital Regional do Cariri, no setor de Organização de Procura de Órgãos (OPO), contavam de 2 a 5 anos de experiência ali.

Foram realizadas 10 perguntas, que serão explanadas. Com a análise das respostas foi realizada uma divisão em quatro categorias: 1. O procedimento utilizado na abordagem familiar; 2. Dúvidas dos familiares quanto à doação de órgãos; 3. Principais desafios dos profissionais da saúde no processo de captação de órgãos; 4. Importância do profissional psicólogo na equipe multidisciplinar do Hospital Regional do Cariri. Assim, poder-se-á perceber e discutir em cada ponto como se dá o processo de captação de múltiplos órgãos no Hospital Regional do Cariri.

Na entrevista, perguntou-se quais órgãos que são captados no Hospital Regional, e todos responderam que podem ser captados coração, pâncreas, rins, fígado e córneas. Um dos enfermeiros complementou afirmando que:

“[...] na maior parte das captações de múltiplos órgãos, costuma acontecer, fígado, rins e córneas. Nos doadores jovens, a gente chegou a captar coração também e já houve captação de pâncreas, no caso pâncreas e rim. Houve algumas vezes que foi captado pâncreas e rim para transplante dos dois órgãos simultâneos”. (E3).

De acordo com Pestana et al. (2013), as circunstâncias que levam a indicação da doação de órgãos seriam, principalmente e depois de várias avaliações, o fechamento do diagnóstico de morte encefálica. Após a constatação da ME, o paciente é considerado potencial doador de órgãos, descartando sempre as contraindicações clínicas que possam causar riscos aos receptores dos órgãos. Como mostra um dos enfermeiros (as):

\footnotetext{
“A doação de órgãos e tecidos é indicada em duas circunstâncias, quando há o diagnóstico de morte encefálica. Depois que é finalizado o protocolo de morte encefálica, esse doador pode ser doador de múltiplos órgãos e tecidos. E durante a situação que há o coração parado, que é a morte por coração parado, esse doador pode doar apenas tecido, e aqui no Regional nós fazemos a captação de córneas, somente". (E1)
}

Todos os entrevistados afirmaram que o processo de doação cresceu, nos últimos anos, após o início do serviço de captação de córneas no HRC. Um dos entrevistados forneceu a quantidade correta de doações desde o início do processo de captação, em 2012, até 2016. Com 
base nos dados obtidos, foi possível perceber um aumento considerável no processo de doação, representado a seguir (Gráfico 1).

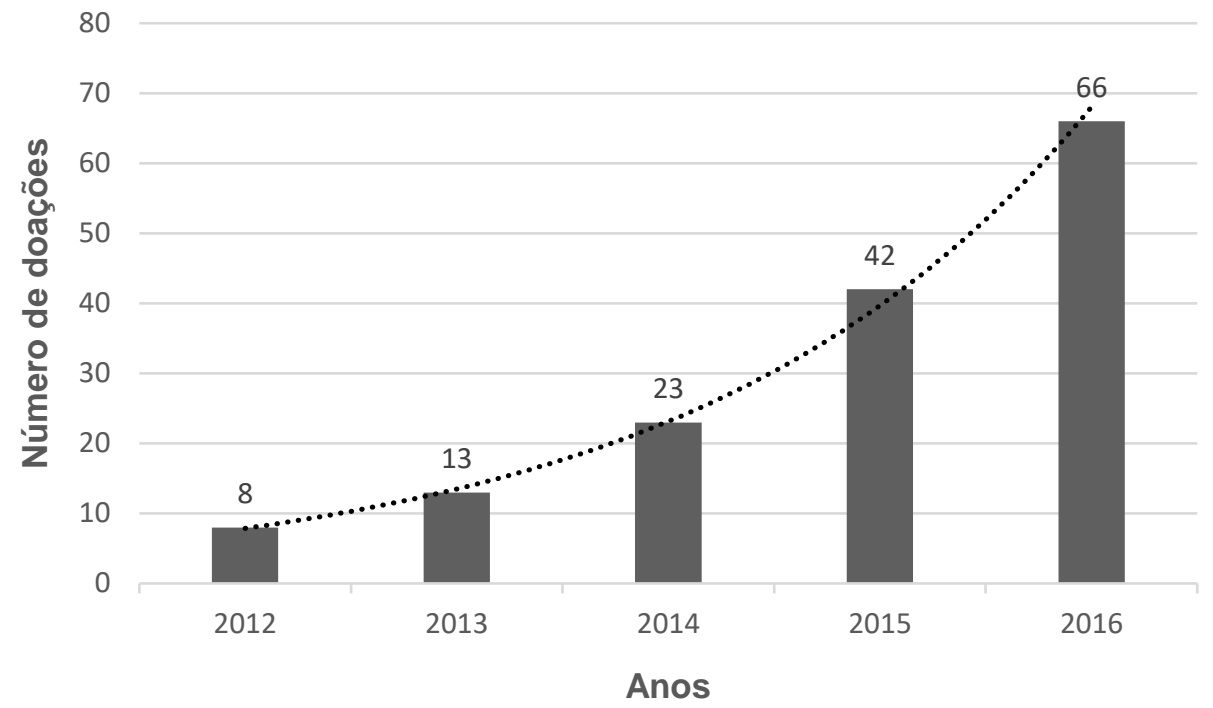

Gráfico 1: Número de Captações de Órgãos no HRC.

O crescimento no processo de captação mostrado no gráfico acima é explicado pela fala de um dos entrevistados:

“[...] Em 2015 o serviço de captação de córnea já estava funcionando bem e esse numero subiu de 23 para 42 doações entre múltiplos órgãos e córneas, durante o ano inteiro de 2015, e 2016 de janeiro a setembro que ta contabilizado até setembro já foram efetivadas 66 doações o que se explica esse crescente aumento? em 2016, pra ser mais preciso, em julho de 2016 iniciou captação de córnea coração parado, aqui no Hospital Regional[...] " (E2)

\section{O procedimento utilizado na abordagem familiar}

De acordo com o questionamento feito acerca da abordagem familiar, os enfermeiros relatam que o procedimento é feito após o diagnóstico de ME a partir da equipe da OPO: 
Id on Line Revista Multidisciplinar e de Psicologia

Id on Line Multidisciplinary and Psycology Journal

“[...] quando finalizado o protocolo de ME, a família, ela é abordada pela OPO, que é a Organização de Procura de Órgãos, então os enfermeiros da OPO é que são as pessoas habilitadas e aqui no Hospital Regional fazem entrevista para doação de órgãos e tecidos [...]" (E1)

Corroborando com a fala de E1, observa-se a fala de E2 e E3:

"[...] os enfermeiros da OPO convidam os familiares para um momento que a gente chama de entrevista familiar, onde a gente apresenta a possibilidade de doação." (E2)

"Só quem realiza a abordagem, a entrevista familiar como a gente chama, são os profissionais capacitados, que somos nós aqui da OPO, CIHDOTT, aqui do Hospital Regional.” (E3)

Para a entrevista familiar, os enfermeiros afirmam que a abordagem deve ser precedida do diagnóstico de ME, como dito anteriormente, realizada pela equipe médica. Depois de um período a equipe responsável pela captação estabelece um melhor momento para conversar com a família e apresentar a oportunidade da doação.

"[...] existe aí a comunicação do óbito que é feita pelo médico assistente, e em seguida a OPO conversa com a família acerca dos procedimentos para doação de órgãos, para tentar a autorização familiar para doação de órgãos e tecidos”. (E1)

Contudo, foi mencionado que, para esse procedimento, a equipe deve passar por um treinamento, que é destacado na fala a seguir:

“[...] recebemos todo um treinamento técnico para realizar essa abordagem, então após o fechamento do diagnóstico, após essa família ter sido comunicada da morte pelo médico assistente, pela equipe assistente, a equipe da OPO ela entra no melhor momento para conversar com essa família e oferecer a oportunidade da doação." (E3)

Como se pode ver, a equipe da OPO, composta por enfermeiros, é responsável pela abordagem familiar. No entanto, surge a curiosidade de saber como acontece a entrevista, fato que é esclarecido na fala dos entrevistados:

"A entrevista familiar, ela é realizada num ambiente confortável, onde você tenha concentrado toda a família, todos os responsáveis legais, e nós só fazemos a entrevista familiar e a conversa com o responsável legal.” (E4) 
“[...] tem toda uma técnica de verificar um local adequado, um local onde todo mundo possa sentar, um local tranquilo, onde não tenha muita interferência, não pode ser em corredores [...]" (E3).

Vale ressaltar que, durante o processo de doação e transplante de órgãos, é a importante acolher e compreender o familiar ante à perda de seu ente querido. Isso facilita a decisão mais apropriada para o familiar, pois, respeitar e compreender o momento do outro é mais importante do que doação em si (DE ALMEIDA et al., 2015).

\section{As dúvidas dos familiares quanto à doação de órgãos}

Diante do diagnóstico de morte encefálica e da possibilidade de doação de órgãos, a família do paciente, possível doador, pode apresentar questionamentos. Foi perguntado quais as possíveis duvidas expostas. Dentre as falas apresentadas, pode-se destacar a seguinte:

“As principais dúvidas, elas estão relacionadas ao procedimento na verdade ao protocolo de morte encefálica, [...] o tempo pra captação de órgãos, eles querem saber quem vai ser o receptor porque eles acreditam que uma parte do filho vai ficar vivo em outras pessoas [...]" (E1)

Quando se refere ao consentimento para doação de órgãos, pode-se sugerir que a família aceitou a perda do ente querido, mas, muitas vezes, ainda tem dúvidas quanto ao diagnóstico da ME e expectativa da reversão do quadro clínico onde ele se encontra (FERNANDES et al., 2015).

"[...] ainda existe umas dúvidas acerca da possibilidade de reversão, às vezes eles não entendem a irreversibilidade da morte encefálica [...] pra quem vai os órgãos, quem vai se beneficiar." (E2)

Nesse sentido, pode-se perceber que essas dúvidas sugerem a recusa para a doação de órgãos. Moraes et al (2009) afirma que o conhecimento dos motivos de recusa pode proporcionar elementos para os profissionais que operam no processo de doação e transplante, que o intuito principal é obter órgãos e efetivar o processo de forma apropriada, seguindo os 
Id on Line Revista Multidisciplinar e de Psicologia

Id on Line Multidisciplinary and Psycology Journal

princípios da ética, da legitimidade e da humanização, não acrescentando mais dor e sofrimento aos familiares do potencial doador.

Corroborando com o autor acima, Almeida (2011) afirma que é importante que a família esteja ciente de todos os procedimentos que acontece com o paciente, antes, durante e após a doação. Especialmente no que se refere à reconstituição do corpo e ao tempo previsto para a entrega do paciente aos familiares enlutados.

Isso também é relatado na fala de alguns dos entrevistados:

\footnotetext{
"A principal dúvida é o tempo, quanto tempo vai demorar isso, sobre a recomposição do corpo, se vai aparentar no velório que houve doação, se o corte fica à mostra né, se a incisão fica à mostra, a sutura, e quem será o receptor, se eles podem ter acesso a quem vai receber os órgãos.” (E3)

"Perguntam se no corpo vai ficar cicatriz; Perguntam para quem vai os órgãos doados [...]" (E5)
}

\section{Os principais desafios dos profissionais da saúde no processo de captação de órgãos}

O consentimento da família dos pacientes, considerados potenciais doadores, é uma grande limitação no sucesso de transplantes de órgãos e tecidos (FERAZZO et al., 2011). O que pode direcionar a decisão quanto à doação é a assistência dada à família por toda a equipe que assiste o doador em potencial. São aspectos relevantes para a realização da entrevista: a opinião, o conhecimento, o esclarecimento e a compreensão dos familiares sobre a evolução do quadro clínico e sobre os procedimentos realizados no potencial doador (SANTOS e MASSAROLLO, 2012).

Todos esses aspectos citados por Santos e Massarollo (2012), influenciam na tomada de decisão por parte da família. Assim, o responsável pela entrevista familiar encontra desafios no processo de captação de múltiplos órgãos, como mostra as falas a seguir:

“[...] a forma como que o médico falou, então a forma com que a família foi atendida no hospital ela influencia muito, então a religião, né? Influencia [...] quando acontece alguma situação que família fique chateada pelo atendimento [...] " (E1) 
A fala acima é elucidada por Santos e Massarollo (2012), quando descreve que a assistência adequada ao potencial doador e o amparo oferecido aos familiares promovem a execução da entrevista familiar e requerem o envolvimento da equipe multiprofissional para abordar a família com integridade e compostura. Esse fato pode ser visto também nos relatos de E2 e E3.

\begin{abstract}
"É, o nosso principal desafio, eu costumo dizer que é a conscientização da equipe multiprofissional [...] outro desafio que eu também considero é o momento da entrevista familiar, que também está relacionado à assistência, a forma que esse familiar foi recebido, foi atendido [...] se o atendimento foi satisfatório [...] se os familiares, eles foram bem atendidos, então assim, é mais a questão da conscientização do profissional [...] o manejo e acolhimento com a família porque isso reflete na entrevista." (E2)

"[...]o desafio é manter a logística bem sincronizada, o que é manter bem sincronizada? É manter a família informada de todo o processo desde o início até o fim $[\ldots] "(\mathrm{E} 3)$
\end{abstract}

Considera-se, então, que o principal desafio para esses profissionais da saúde está diretamente relacionado à conscientização da equipe multiprofissional e ao bom atendimento a família desde o início da internação do possível doador até o momento da entrevista familiar, para possibilidade de doação.

Todo este profissionalismo da equipe refletirá posteriormente na decisão da família sobre a captação de órgãos. Esse fato corrobora a ideia de Pimenta et al. (2012), quando este relata que a doação de órgãos positiva depende da confiança estabelecida entre a equipe multiprofissional e a família do potencial doador, bem como da rapidez do processo de confirmação do diagnóstico da ME. Fernandes et al. (2015) chegou a mesma conclusão, assegurando o que foi descrito por Pimenta et al. (2012). Ele comenta que a relação entre a equipe multiprofissional e a família do doador é um indicador importante do processo de doação. 
Id on Line Revista Multidisciplinar e de Psicologia

Id on Line Multidisciplinary and Psycology Journal

\title{
A importância do profissional psicólogo na equipe multidisciplinar do Hospital Regional do Cariri.
}

Uma pesquisa realizada por Saldanha et al. (2013) mostra a importância do psicólogo no ambiente hospitalar. Descreve que toda a equipe ouve as angústias e os temores do paciente, porém o profissional psicólogo é quem possui o olhar e o cuidado na escuta. O paciente necessita de zelo da equipe médica, da equipe de enfermagem, e da intervenção psicológica. É imprescindível suprir as dúvidas sobre a doença com o paciente para que ele possa compreender o efeito que este fato tem concebido em sua vida.

A equipe de captação de órgão é composta por profissionais da enfermagem que ficam responsáveis pela abordagem e pelo acolhimento da família. Assim, os enfermeiros enfrentam desafios diante dessa situação. Essa problemática se dá devido à falta de preparo durante o período da graduação, o que é confirmado pela declaração a seguir:

\footnotetext{
"Durante a graduação, na verdade, a gente não recebe muito preparo acerca desses procedimentos de diagnósticos de morte encefálica entrevista família, enfim, isso só aconteceu depois mesmo da minha graduação, com o início do trabalho, né? Hoje, com o tempo, a gente vai se adaptando a esse processo porque todos os dias a gente tem entrevista com uma família nessa situação”. (E1)
}

A maior dificuldade sentida pelos enfermeiros é o momento da entrevista familiar:

\begin{abstract}
"Na verdade o principal desafio, o momento ápice do processo é realmente o da entrevista familiar [...] a gente tem que se preparar emocionalmente e conversar com a família no momento que é mais difícil para ela, que é assim que ela recebe a notícia do óbito, então esse realmente o principal desafio [...] que acaba tendo várias influências do doador, da família, do atendimento hospitalar, do processo." (E1)
\end{abstract}

Para que este processo aconteça com qualidade, o profissional deve encontrar um ponto de equilíbrio lidar os conflitos pessoais que a confrontação com a morte do outro lhe provoca, o que nos leva a discutir como estão sendo preparados esses profissionais para operarem com tais questões que envolvem tanta emoção (DE ALMEIDA et al., 2015).

Com o exposto acima, fica evidente a relevância da presença de um profissional capacitado para preparar a equipe e atender as necessidades da família durante o acolhimento, 
Id on Line Revista Multidisciplinar e de Psicologia

Id on Line Multidisciplinary and Psycology Journal

por se tratar de um momento delicado e de decisão rápida. Sendo assim, o psicólogo entra como um membro importante nesse processo. Fato que foi confirmado por todos os entrevistados.

\begin{abstract}
"Eu acho que seria interessante, desde o início junto [...] e principalmente no momento da entrevista, na comunicação da má noticia, né? Quando o médico vai comunicar o óbito, eu acho que o psicólogo teria esse preparo né? Esse manejo, a forma de conversar com a família no momento dessa comunicação dessa má notícia. " (E1)

"Se tivesse um profissional psicólogo, que acompanhasse essas etapas, que conseguisse dar assistência que aquela família precisa, eu não tenho dúvida que a gente iria ter resultados melhores." (E2)
\end{abstract}

E3 e E5 expõem que a presença do psicólogo na equipe multidisciplinar ajudaria na entrevista e daria suporte à família nesse momento delicado de aceitação da morte e de decisão da doação de órgãos. Complementando, E4 relata que além do amparo às famílias seria importante também o acompanhamento dos profissionais envolvidos no processo.

\footnotetext{
"Um Psicólogo é importante na questão da entrevista familiar. Sentir essa família e dar suporte a essa família, acho que é interessante [...] e eu acho que um profissional psicólogo acompanharia muito bem o processo para dar um suporte àquela família, [...] que muitas vezes nós enfermeiros, apesar de treinados para realizar essa entrevista, não sabemos lidar muitas vezes com determinadas atitudes né?!.” (E3)

"É importante, importante porque existe o acompanhamento para os profissionais, como também pode existir o acompanhamento para as famílias, a família do que está acabando de perder como a família que perdeu e não consegue curar o luto." (E4)

"Um profissional da psicologia ajudaria no processo de entrevista familiar e acompanhamento dos familiares." (E5)
}

Torres e Lage (2013) afirma que o psicólogo pode favorecer os familiares enlutados a falar sobre morte e sobre o processo de despedida, ajudando-os na demonstração de sentimentos com o apoio emocional necessário. Sendo assim, a orientação psicológica a esses familiares para os rituais é imprescindível, pois respeita a vontade, os limites e a forma pessoal de cada familiar lidar com essas situações.

Destaca-se a necessidade de um profissional psicólogo inserido na equipe multiprofissional, auxiliando os membros da equipe, acompanhando os familiares desde o momento da internação do possível doador até o momento da entrevista, o qual, com um olhar 
Id on Line Revista Multidisciplinar e de Psicologia

Id on Line Multidisciplinary and Psycology Journal

mais subjetivo, poderá amparar aqueles familiares para uma melhor compreensão sobre a morte do ente querido, ajudando no emocional e dando suporte para o processo de doação de órgãos.

\section{Conclusões}

Em vista dos argumentos apresentados, e durante a execução do trabalho percebeu-se que foi verificado os aspectos que envolvem os profissionais da saúde e familiares, no que se refere aos sentimentos e emoções que todos passam durante todo o percurso, desde a internação do possível doador até o processo de captação de órgãos.

Através da entrevista com os enfermeiros da OPO observou-se que a entrevista familiar é uma etapa bastante importante no processo de captação, por se tratar da possibilidade de doação para salvar vidas de outras pessoas que necessitam de um transplante. Contudo, se torna complexo devido o envolvimento emocional dos familiares e do entrevistador.

No tocante aos objetivos expostos é possível destacar a importância que o profissional psicólogo apresenta, e a contribuição dele para com a equipe de saúde multiprofissional no auxilio com o acolhimento e a escuta aos familiares enlutados. Oferecendo também, suporte psicológico com um olhar mais subjetivo, para assim possibilitar uma melhor elaboração do luto por um falecido, a compreensão sobre a morte encefálica e facilitar o processo de captação de órgãos.

Por fim, esse trabalho não pretende esgotar o tema, destacamos a necessidade de serem desenvolvidas mais pesquisas nesta linha para melhorar os conhecimentos dos envolvidos no processo, buscando caminhos para implementar uma assistência que contemple as reais necessidades das pessoas enlutadas, facilitando o processo de captação tanto para os profissionais da saúde quanto para os familiares. Espera-se também que os resultados da pesquisa levem os profissionais de saúde a refletirem e conscientizarem-se sobre a necessidade do psicólogo na equipe multiprofissional. 
Id on Line Revista Multidisciplinar e de Psicologia

Id on Line Multidisciplinary and Psycology Journal

\section{Referências}

AGUIAR, Maria Isis Freire de et al. Perfil de doadores efetivos de órgãos e tecidos no estado do Ceará. Revista Mineira de Enfermagem, v. 14, n. 3, p. 353-360, 2010.

ALMEIDA, Elton Carlos de. Doação de órgãos e visão da família sobre atuação dos profissonais neste processo: revisão sistemática da literatura brasileira. 2011. Tese de Doutorado. Universidade de São Paulo.

AZEVEDO, Ana Karina Silva; PEREIRA, Sra Maria Aldeci. O luto na clínica psicológica: um olhar fenomenológico. Clínica \& Cultura, v. 2, n. 2, p. 54-67, 2014.

BITTENCOURT, Ana Luiza Portela; QUINTANA, Alberto Manuel; VELHO, Maria Teresa Aquino de Campos. A perda do filho: luto e doação de órgãos. Estud. psicol., Campinas, v. 28, n. 4, dez. 2011. Disponível em <http://dx.doi.org/10.1590/S0103-166X2011000400004>. Acesso em: 20 out. 2016.

BRASIL. Lei n. 9.434, de 4 de fevereiro de 1997. Legislação brasileira sobre doação de órgãos tecidos e partes do corpo humano para fins de transplante e tratamento, e legislação correlata. Centro de Documentação e Informação Coordenação de Publicações Brasília. Série: Fontes de referência. Legislação n. 41. 2002.

Lei n. ${ }^{\circ}$ 10.211, de 23 de março de 2001. Altera dispositivos da Lei no 9.434, de 4 de fevereiro de 1997, que dispõe sobre a remoção de órgãos, tecidos e partes do corpo humano para fins de transplante e tratamento. Diário Oficial [da] República Federativa do Brasil, Brasília, DF, 23 mar. 2001. Disponível em: <http://www.planalto.gov.br/ccivil_03/leis/LEIS_2001/L10211.htm\#art1>. Acesso em: 06 set. 2016.

Secretaria de Estado da Saúde de São Paulo. Sistema Estadual de Transplantes. Lista de espera por órgão e córnea - 2010. Lista de espera para transplante, com doador cadavérico, no Estado de São Paulo. São Paulo: Secretaria de Estado da Saúde de São Paulo, 2010. [citado 2011 Ago 5]. Disponível em: http://www.saude.sp.gov.br/ses/perfil/gestor/ informacoes-de-saude_1/transplantesem-dados/lista-de-espera-pororgao-e-cornea-2012

CAJADO, MCV. Doar ou não doar, eis a questão: impasses subjetivos no processo de doação de órgãos e tecidos para transplantes. Dissertação de mestrado do Programa de PósGraduação em Família na Sociedade Contemporânea da Universidade Católica de Salvador. 2011. 202p. Disponível em:<http://tede.ucsal.br/tde_arquivos/1/TDE-2011-12-13T160914Z214/Publico/MARIA\%20CONSTANCA\%20VELLOSO\%20CAJADO.pdf > Acessado em: 20 de out. de 2016.

CARVALHO, Aline Luiza. Realidade suplementar para famílias em processo de doação de órgãos para transplantes. Revista Brasileira de Psicodrama, v. 23, n. 2, p. 75-81, 2015. 
Id on Line Revista Multidisciplinar e de Psicologia

Id on Line Multidisciplinary and Psycology Journal

CINQUE, Valdir Moreira.; BIANCHI, Estela Regina Ferraz. A tomada de decisão das famílias para a doação de órgãos. Cogitare Enferm. 15(1):69-73. 2010a;

Estressores vivenciados pelos familiares no processo de doação de órgãos e tecidos para transplante. Revista da Escola de Enfermagem da USP, v. 44, n. 4, p. 996-1002, 2010 b.

DE ALMEIDA, Elton Carlos; BUENO, Sonia Maria Villela; BALDISSERA, Vanessa Antoniassi Denardi. ATUAÇÃO DE PROFISSIONAIS DE SAÚDE EM DOAÇÃO DE ÓRGÃOS NA PERSPECTIVA DO FAMILIAR: UMA ANÁLISE PROBLEMATIZADORA. Arquivos de Ciências da Saúde da UNIPAR, v. 19, n. 2, 2015.

DE JESUS SOUZA, B. S. DE J .; LIRA, G. G.; MOLA, R. Notificação da morte encefálica em ambiente hospitalar. 2016.

DELALIBERA, MAYRA et al. A dinâmica familiar no processo de luto: revisão sistemática da literatura. Ciência \& Saúde Coletiva, v. 20, n. 4, p. 1119-1134, 2015.

DELL AGNOLO, C. M. et al. Causes of organ donation failure in Brazil. In: Transplantation proceedings. Elsevier, 2012. p. 2280-2282.

FELIÚ, XIMENA. Enfrentando a morte: a experiência de luto em famílias de doadores de órgãos e tecidos. Monografia do Curso de Aprimoramento Teoria, Pesquisa e Intervenção em Luto. 4 Estações Instituto de Psicologia. São Paulo, 2009.

FERAZZO, Sílvia et al. Crença religiosa e doação de órgãos e tecidos: revisão integrativa da literatura. Revista de Enfermagem da UFSM, v. 1, n. 3, p. 449-460, 2011.

FERNANDES, Marli Elisa Nascimento; DE CAMARGO BITTENCOURT, Zélia Zilda Lourenço; BOIN, Ilka de Fátima Santana Ferreira. Vivenciando a doação de órgãos: sentimentos de familiares pos consentimento. Revista Latino-Americana de Enfermagem, v. 23, n. 5, p. 895-901, 2015.

FREIRE, I. L. S.; MENDONÇA, A.E.O.; DANTAS, B.A.S.; SILVA, M.F.; GOMES, A.T.L.; TORRES, G.V. Process of organ and tissue donation for transplant: Reflections about its effectiveness. Journal of Nursing UFPE on line [JNUOL/DOI: 10.5205/01012007/Impact factor: RIC: 0, 9220], v. 8, n. 7, p. 2533-2538, 2014.

FREIRE, S. G.; FREIRE, I.L.S.; PINTO, J.T.J.M.; VASCONCELOS, Q.L.D.A.Q.; TORRES, G.D.V. Alterações fisiológicas da morte encefálica em potenciais doadores de órgãos e tecidos para transplantes. Esc Anna Nery. 2012; 16(4):761-6.

FUKUMITSU, K.O.; KOVÁCS, M. J. Especificidades sobre processo de luto frente ao suicídio. Psico, v. 47, n. 1, p. 3-12, 2016. 
Id on Line Revista Multidisciplinar e de Psicologia

Id on Line Multidisciplinary and Psycology Journal

FURLAN, A. C.; ESPOLADOR, R. de C. R. T.; MAZIERO, K. M. C. Disposição de Órgãos para Transplante. Revista de Ciências Jurídicas e Empresariais, v. 11, n. 1, 2015.

GIL, Antonio Carlos. Como Elaborar Projetos de Pesquisa. 5a ed. São Paulo: Atlas, 2010.

GUIMARÃES, C. A.; LIPP, M. E. N. Um olhar sobre o cuidador de pacientes oncológicos recebendo cuidados paliativos. Psic: Teo Prát 2011; 13(2):50-62.

KNIHS, Neide da Silva; SCHIRMER, Janine; ROZA, Bartira de Aguiar. Adaptación del modelo español de gestión en trasplante para la mejora en la negativa familiar y mantenimiento del donante potencial. Texto \& Contexto-Enfermagem, 2011.

KRAMER, B. J., KAVANAUGH, M.; TRENTHAM-DIETZ, A.; WALSH, M.; YONKER, J. A. Complicated grief symptoms in caregivers of persons with lung cancer: The role of family conflict, intrapsychic strains, and hospice utilization. Omega J Death Dying 2010; 62(3):201-220.

KÜBLER-ROSS, E. Sobre a Morte e o Morrer: o que os doentes têm para ensinar a médicos, enfermeiras, religiosos e aos próprios parentes. $7^{\mathrm{a}}$ ed.- São Paulo: Martins Fontes, 1996.

LADESSA, Lilian Elizabeth Cassia Leite; SILVA, Simone Corrêa; DE OLIVEIRA, Priscilla Caroliny. REFLEXÕES SOBRE O TRABALHO DO PSICÓLOGO NO PROCESSO DE DOAÇÃO DE ÓRGÃOS. Blucher Medical Proceedings, v. 1, n. 6, p. 22-25, 2014.

MARINHO, Alexandre; CARDOSO, Simone de Souza; ALMEIDA, Vivian Vicente de. Organ transplantation in Brazilian States: effectiveness, productivity, and capacity. Cadernos de Saúde Pública, v. 27, n. 8, p. 1560-1568, 2011.

MENDES, Karina Dal Sasso et al. Transplante de órgãos e tecidos: responsabilidades do enfermeiro. Texto \& Contexto-Enfermagem, v. 21, n. 4, p. 945-953, 2012.

MIRANDA AFONSO, M. L. (2011). Notas sobre sujeito e autonomia na intervenção psicossocial. Psicologia em Revista, 17(3), 445-464.

MORAES, Edvaldo Leal de et al. Recusa de doação de órgãos e tecidos para transplante relatados por familiares de potenciais doadores. Acta paul enferm, v. 22, n. 2, p. 131-5, 2009.

MORATO, E. G. Morte encefálica: conceitos essenciais, diagnóstico e atualização. Rev Med Minas Gerais. 2009;19(3):227-36.

NORONHA M. G. O, et al. Estudo do perfil dos doadores elegíveis de órgãos e tecidos e motivos da não doação no Hospital Santa Isabel em Blumenau, SC. Rev AMRIGS. 2012; 56(3):199-203. 
Id on Line Revista Multidisciplinar e de Psicologia

Id on Line Multidisciplinary and Psycology Journal

OSSWALD, Walter. Sobre a morte e o morrer. FUNDAÇÃO FRANCISCO MANUEL DOS SANTOS, 2016.

PALMEIRA, H.; SCORSOLINI-COMIN, F.; PERES, R.S. Cuidados paliativos no Brasil: revisão integrativa da literatura científica. Aletheia 2011;35/36:179-189.

PARKES, C. M. Luto: estudo sobre a perda na vida adulta. Summus Editorial: São Paulo, 1998.

PESTANA, Aline Lima et al. Pensamento Lean e cuidado do paciente em morte encefálica no processo de doação de órgãos. Revista da Escola de Enfermagem da USP, v. 47, n. 1, p. 258-264, 2013.

PIMENTA, Fernanda de Paula; AMORIM, Bárbara Rios Vellasco; SILVA, Ledismar José. Morte encefálica: diagnóstico possível sem utilização de exames complementares. Arq. bras. neurocir, v. 31, n. 1, 2012.

ROZA, B. A. et al. Doação de órgãos e tecidos: relação com o corpo em nossa sociedade. Acta Paul Enferm. 2010;23(3):417-22.

ROZA, B. A. Efeitos do processo de doação de órgãos e tecidos em familiares: intencionalidade de uma nova doação. São Paulo: 2005. Dissertação de mestrado, Universidade Federal de São Paulo.

SADALA, M.L.A. Doação de órgãos: a experiência de enfermeiras, médicos e familiares de doadores. São Paulo: Editora UNESP, 2004.

SALDANHA, Shirlei de Vargas; ROSA, Aline Badch; CRUZ, Lilian Rodrigues da. O Psicólogo Clínico e a equipe multidisciplinar no Hospital Santa Cruz. Revista da SBPH, v. 16, n. 1, p. 185-198, 2013.

SANTOS, M.J.; MASSAROLLO, Maria Cristina Komatsu Braga. Processo de doação de órgãos: percepção de familiares de doadores cadáveres. Rev Latinoam Enferm. 2005;13(3):382-7.

Entrevista familiar no processo de doação de órgãos e tecidos para transplante. Acta Paulista de Enfermagem, v. 25, n. 5, p. 788-794, 2012.

Fatores que facilitam e dificultam a entrevista familiar no processo de doação de órgãos e tecidos para transplante. Acta Paulista de Enfermagem, v. 24, n. 4, p. 472-478, 2011.

SANTOS, Marcelo José dos. A entrevista familiar no processo de doação de órgãos e tecidos para transplante. Dissertação (Mestrado) - Escola de Enfermagem, Universidade de São Paulo, 2010. Disponível em: Acesso em: 15 abr. 2013. 
SILVA, Andressa Hennig; FOSSÁ, Maria Ivete Trevisan. Análise de conteúdo: Exemplo de aplicação da técnica para análise de dados qualitativos. Qualitas Revista Eletrônica, v. 16, n. $1,2015$.

SILVA, F.; JUNQUEIRA, C. R. A.; MACÁRIO, T. T. S. Projeto educativo sobre doação de órgãos em sala de aula. JBT J Bras Transpl.15(4):1689-1714. 2012.

SILVA, R. C. da. A falsa dicotomia qualitativo-quantitativo: Paradigmas que informam nossas práticas de pesquisas. Diálogos metodológicos sobre prática de pesquisa, p. 159-174, 1998.

SIMINOFF, L. A; ARNOLD, R. M; HEWLETT, J. The process of organ donation and its effect on consent. Clin Transplant,15:39-47. 2001.

SOUZA, R. P. Rotinas de Humanização em Medicina Intensiva. São Paulo: Atheneu, 2010.

STAKE, R. E. Pesquisa qualitativa: estudando como as coisas funcionam. Porto Alegre: Penso, 2011.

TORRES, Juliana Carneiro; LAGE, Ana Maria Vieira. Manifestações psicológicas de familiares com pacientes em morte encefálica. Revista de Psicologia, v. 4, n. 1, 2013.

TRIVIÑOS, A. N. da S. Introdução à pesquisa em ciências sociais: a pesquisa qualitativa em educação. São Paulo: Atlas, 2008.

VIEIRA, M. S.; NOGUEIRA, L. T. O processo de trabalho no contexto da doação de órgãos e tecidos [The work process in the context of organ and tissue donation]. Revista Enfermagem UERJ, v. 23, n. 6, p. 825-831, 2016.

WIJDICKS, E.F.M. The diagnosis of brain death. N Engl J Med. 344:1215- 1221. 2001.

Como citar este artigo (Formato ABNT):

LEITE, Naianne F.; MARANHÃO, Thércia L. G.; FARIAS, Athena de A. Captação de Múltiplos órgãos: os desafios do processo para os Profissionais de Saúde e Familiares . Id on Line Revista Multidisciplinar e de Psicologia, Fevereiro de 2017, vol.11, n.34, p. 246-270. ISSN: 1981-1179.

Recebido: 06.02.2017

Aceito: 27.02.2017 